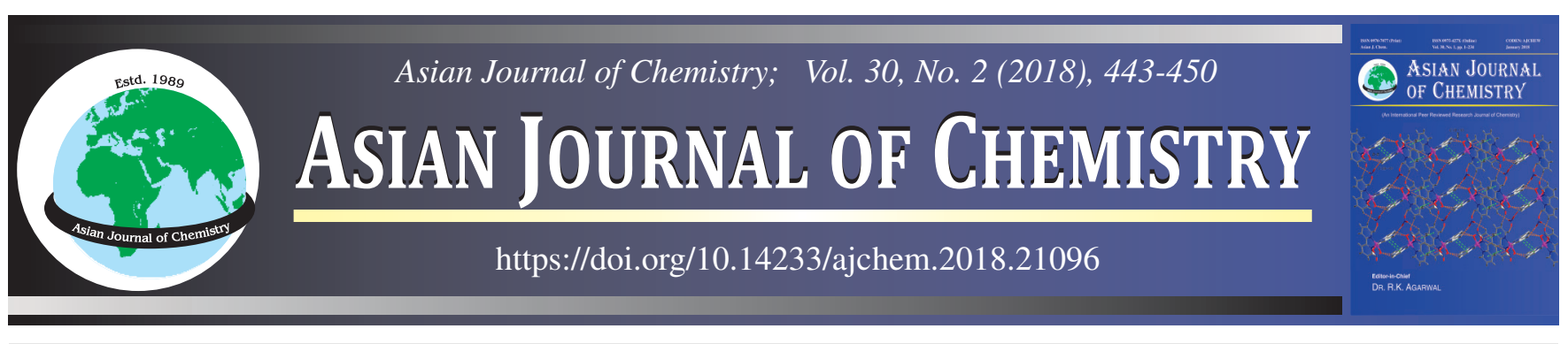

\title{
Development of Porous Polysaccharides-Hydroxyapatite Composite Scaffolds via Freeze Drying Method and in vitro Osteoconductivity on MG 63 Cells
}

\author{
R. Rajesh ${ }^{1,2}$, S.K. Ashok Kumar ${ }^{3, *}$, Dunkana Negussa Kenie ${ }^{4}$ and Y. Dominic Ravichandran ${ }^{1,4, *}$
}

${ }^{1}$ Department of Science and Humanities, Karpagam College of Engineering, Coimbatore-641 032, India

${ }^{2}$ Department of Chemical Engineering, National Chung Cheng University, Chia-Yi, Taiwan 62102, P.R China

${ }^{3}$ Department of Chemistry, School of Advanced Sciences, Vellore Institute of Technology, Vellore-632 014, India

${ }^{4}$ Department of Chemistry, College of Natural and Computational Sciences, Wollega University, Nekemete, Ethiopia

*Corresponding authors: Fax: 91416 2243092; +91 416 2245766, E-mail: ashokkumar.sk@ vit.ac.in; ydominic64@yahoo.co.in

\begin{abstract}
Tricomponent scaffolds of hydroxyapatite (HAP) with a mixture of polysaccharides have been prepared by freeze drying method and TG, FTIR, XRD and FE-SEM. FTIR and powder XRD analysis were confirmed the formation of composites with strong electrostatic interactions. FE-SEM images showed the porous morphology of the prepared tricomponent scaffolds. The cell proliferation and mineralization of the scaffolds were evaluated through in vitro MTT assay and alkaline phosphatase activity on MG 63 cell line. The study proved that the prepared tricomponent scaffolds have better cell proliferation and mineralization. Moreover, the well dispersion and adhesion of cells on to the scaffolds were evident from the dye stained fluorescent microscopic images. Porosity of the prepared tricomponent scaffolds plays a vital role, which is well corroborated from the higher cell proliferation and mineralization of chitosan/gellan-HAP scaffold. The viscosity and porosity of the scaffolds play a crucial role on the compressive strength of prepared scaffolds.

Keywords: Polysaccharides, Hydroxyapatite, Scaffolds, Tissue engineering.
\end{abstract}

\section{INTRODUCTION}

Bone formation is the result of sequential events that begin with recruitment and proliferation of osteoprogenitor cells from surrounding tissues, followed by osteoblastic differentiation, matrix formation and mineralization [1]. Current medical treatment for bony defects including allograft, autograft and metal implants offer several complications, such as insufficient osteointegration, increased risk of infection at the implant size, disease transmission and required secondary surgery, all of which may lead to implant failure. These limitations in current bony defect treatments need an alternative and a new set of biomaterials [2-4]. Bone tissue engineering has been considered as a promising alternative method for the current treatment. In tissue engineering, natural polymers provide a support for matrices or as substrates for the delivery of bioactive species and cultured cells to defect site and to promote three dimensional (3D) tissue reconstructions. The 3D scaffolds have the advantage of bio-mimicking the natural extracellular matrix (ECM). Extracellular matrix is an intricate network of collagen and elastic fibers embedded in a hydrated gel like materials of glycosaminoglycans, proteoglycans and glycoproteins. Naturally derived ECM components of polysaccharides constituents could serve as a suitable material to design scaffolds, since they are biocompatible, non-antigenic, non-immunogenic, similarity with ECM and intrinsic cellular interactions. Further, these materials act as a temporary skeleton inserted into the defective sites of skeleton or lost bone sites in order to support and stimulate bone tissue regeneration while they gradually degrade and is finally replaced by new bone tissue. Furthermore, natural polymers provide a great deal of flexibility with respect to their tunable mechanical properties and natural degradation time within the body [5-8].

The hydrophilic group of polysaccharides has the ability to promote the growth of dense mineralized bone tissue, cell adhesion, proliferation, differentiation and bone formation within the defective site after its implantation through electrostatic interactions [9-14]. Some of the most widely used polysaccharides in tissue engineering are alginate, amylopectin, agar, chitosan, cellulose, dextran, gellan, hyaluronic acid, glycosaminoglycans, pectins, pullulan, starch and xanthan. The polysaccharides are currently not exclusively used for tissue engineering due to their jelly-like consistency and insufficient mechanical properties. In order to meet the desired requirement, the polysaccharides applicable in tissue engineering are usually combined with other natural or synthetic polymers or 
reinforced with inorganic minerals to increase mechanical strength $[9,10,15,16]$.

Natural bone is generally composed of $70 \%$ inorganic minerals of hydroxyapatite (HAP) and $30 \%$ organic materials (major collagen). Hydroxyapatite has been widely used as biocompatible ceramic material in medicine mainly for bone tissue engineering because of its ability to bond chemically with living bone tissue. It owes resemblance of chemical, compositional, biological and crystal structural properties of the native apatite in human skeleton [17-19]. Further, HAP is reinforced with polysaccharides to mimic the role of inorganic minerals as well as to overcome the insufficient mechanical strength. Several reports are available to synthesis and isolate HAP from natural sources including fish bone, pig bone and teeth, goat bone and chicken bone. Hydroxyapatite isolated from natural bones is carbonated and have better biocompatibility, osteocondution and bioresorption than the synthesized HAP. Hence, carbonated HAP was isolated from chicken bones for this work, with the various references from literature [20-22].

Several methods have been reported to prepare $3 \mathrm{D}$ porous scaffolds which include gas forming, 3D printing, phase separation, porogen leaching, solvent casting/particulate leaching and freeze drying. Freeze drying is generally used in the preparation of polysaccharide scaffolds because this technique is beneficial for polysaccharides in aqueous media, where as synthetic polymeric scaffolds are prepared using organic solvents. Freeze drying process avoids the use of organic solvents and porogen to create porosity, which reduces the toxicity induced by residual compounds. Further, it is simple, cost effective and environmental friendly since water is used as solvent. Moreover, water has the advantage of being functioning as a porogen upon freezing [23,24]. Several two component porous scaffold composed of polysaccharide and HAP have been prepared by freeze drying method which include gellan-HAP [25], chitosan-alginate [26], chitosan-HAP [27] and alginateHAP [28] for bone tissue engineering. In order to improve osteoconduction and biocompatibility of scaffold, binary mixtures of polysaccharide. Hence, the present work chitosan/ gellan-HAP and chitosan/alginate-HAP scaffolds are developed by freeze drying techniques and their potential for bone tissue engineering applications are evaluated and compared with reported chitosan/amylopectin-HAP scaffold [20].

\section{EXPERIMENTAL}

Hydroxyapatite was isolated from the chicken bones (purchased from local slaughterhouse) by the thermal calcinations method. The MG 63 cell line was obtained from the National Center for Cell Science, Pune, India. Chitosan powder (degree of deacetylation $90 \%$ with molecular weight $310 \mathrm{kDa}$ ) was purchased from Wako Pure Chemical Industries Ltd., Japan. Gellan gum, amylopectin, sodium alginate, 3-(4,5-dimethylthiazol-2-yl)-2,5-diphenyltetrazolium bromide (MTT), acridine orange and Bisbenzimide Hoechst 33342 stains were purchased from Sigma Aldrich, India. Dulbecco's Modied Eagle's Medium (DMEM) was purchased from HIMEDIA. Sodium phosphate buffer, $\mathrm{NaCl}$ and $\mathrm{KCl}$ were purchased from Merck. Acetic acid and $\mathrm{NaOH}$ (AR grade) were purchased from S.D. fine chemicals.
Isolation of HAP from chicken bone: Hydroxyapatite was isolated by thermal calcinations method as reported previously by our group [18]. Chicken bones were washed with $1 \mathrm{~N} \mathrm{NaOH}$ solution followed by rinsing with water to remove the traces of meat, skin and other impurities present on the surface of the bones. Then bones were dried in hot air oven at $100{ }^{\circ} \mathrm{C}$ and grained into small pieces. Pretreated chicken bones were subjected to thermal calcinations at $800{ }^{\circ} \mathrm{C}$ with $20 \mathrm{~h}$ holding time in muffle furnace (SUNSIM, India).

Preparation of scaffold materials: Tricomponent scaffolds were prepared as reported by Rajesh et al. [4] and Venketesan et al. [20]. $0.9 \mathrm{~g}$ of chitosan was dissolved in $100 \mathrm{~mL}$ of $2 \%$ acetic acid solution, stirred for $3 \mathrm{~h}$ and then it was sonicated for $30 \mathrm{~min}$. $4.2 \mathrm{~g}$ of HAP was suspended in $50 \mathrm{~mL}$ water and was transferred in to a chitosan solution dropwise. For chitosan/ gellan-HAP scaffold, $0.9 \mathrm{~g}$ of gellan was slowly added to the chitosan-HAP solution and stirred for $24 \mathrm{~h}$. The resultant composite solution mixture was transferred into 12 well plates with $2 \mathrm{~g}$ solution per well. The samples were freeze dried at $-80^{\circ} \mathrm{C}$ and lyophilized with a freeze dryer to form scaffold. These scaffolds were immersed in $10 \% \mathrm{NaOH}$ solution for $24 \mathrm{~h}$ and then washed several times with distilled water to become neutral. All the neutralized scaffolds were lyophilized again. For chitosan/ amylopectin-HAP scaffold, $0.9 \mathrm{~g}$ of amylopectin was slowly added to chitosan-HAP solution and rest of the procedure was followed as that for chitosan/gellan-HAP scaffold. For chitosan/ alginate-HAP scaffold, $0.9 \mathrm{~g}$ of amylopectin was slowly added to chitosan-HAP solution and rest of the procedure was followed as that for chitosan/gellan-HAP scaffold.

General characterization: The thermal stability of the composite scaffold was studied using thermogravimetric (TG) analysis (SDTQ 600 TA Instrument, USA) with scan range of 50 to $800{ }^{\circ} \mathrm{C}$ at a constant heating rate of $10{ }^{\circ} \mathrm{C} / \mathrm{min}$ in the nitrogen atmosphere. The vibrational frequency of the samples were studied by Fourier transform infrared spectroscopy (FTIR) (Jasco FTIR4100, Japan) and the spectrum was recorded within the range of $4000-500 \mathrm{~cm}^{-1}$ using $\mathrm{KBr}$ pellet method. The phase and crystallinity of the samples were examined by powder X-ray diffraction (XRD) (Bruker, D8 Advance X-ray Diffraction spectrophotometer, German) at room temperature using $\mathrm{CuK}_{\alpha}$ as the radiation source with the wavelength $1.504 \AA$, over the angle range $10^{\circ}$ to $80^{\circ}$, step size $0.02^{\circ}$ and scan speed $0.5^{\circ} / \mathrm{min}$. The resultant XRD profile of the isolated HAP was compared with the Standard Joint Committee on Powder Diffraction Standards (JCPDS) cards available in the system software. Further, the morphology of the tricomponent scaffolds was studied by field emission scanning electron microscopy (FESEM) (SUPRA 55, Carl Zeiss, Germany) analysis.

Porosity measurements: Porosity is an important property for the cell proliferation. The total porosity of the scaffold was obtained by the liquid displacement method. Ethanol was used as the displacement liquid because it could easily penetrate into the pores of the scaffolds and did not cause shrinkage and swelling and the scaffolds would not be dissolved in ethanol at room temperature. Initially, the volume of dry ethanol and dry weight of the scaffold was measured $[6,20]$. Then the scaffold was immersed in dry ethanol for $48 \mathrm{~h}$. After $48 \mathrm{~h}$, a scaffold was taken out from ethanol and the weight of the 
scaffold were measured. The total porosity was calculated using the equation, Porosity $=(\mathrm{W} 1-\mathrm{W} 3) /(\mathrm{W} 2-\mathrm{W} 3)$; where $\mathrm{W} 1$ = initial weight of the scaffold, W2 = sum of weights of ethanol and submerged scaffold, W3 = weight of ethanol after the removal of scaffold.

In vitro cell proliferation assay of scaffolds: The MG63 cells were plated separately in 96 well plates at a concentration of $1 \times 10^{5}$ cells/well. After $24 \mathrm{~h}$, cells were washed twice with $100 \mu \mathrm{L}$ of serum-free medium and starved for $1 \mathrm{~h}$ at $37^{\circ} \mathrm{C}$. After starvation, cells were seeded with the scaffold material, which was previously sterilized with $75 \%$ alcohol followed by $100 \%$ alcohol. Cells treated without scaffold material was used as a control. At the end of the treatment period of 1, 2, 3 and 4 days, the medium was aspirated and serum free medium containing MTT $(0.5 \mathrm{mg} / \mathrm{mL})$ was added and incubated for $4 \mathrm{~h}$ at $37^{\circ} \mathrm{C}$ in a $\mathrm{CO}_{2}$ incubator. The determinations were performed using three replicates each time.

The MTT containing medium was then discarded and the cells were washed with phosphate buffer solution (PBS) (200 $\mu \mathrm{L}$ ). The formed formazan crystals were then dissolved by adding $100 \mu \mathrm{L}$ of DMSO and this was mixed properly by pipetting up and down. Spectrophotometrical absorbance of the purple blue formazan dye was measured in a microplate reader at $570 \mathrm{~nm}$ (Biorad 680) [20,29]. Cytotoxicity was determined using Graph pad prism 6 software.

Alkaline phosphatase assay: For the determination of alkaline phosphatase (ALP) activity, cells were cultured as per the cytotoxicity analysis, after the incubation with scaffolds for 2 and 4 days, the cells were treated with $10 \mu \mathrm{L}(100 \mathrm{mmol} / \mathrm{L})$ of $p$-nitrophenyl phosphate and incubated for $30 \mathrm{~min}$ at $37^{\circ} \mathrm{C}$ in a $\mathrm{CO}_{2}$ incubator. Alkaline phosphatase can hydrolyze the $p$-nitrophenyl phosphate in to $p$-nitrophenol and inorganic phosphate [2]. The released $p$-nitrophenol absorbance was measured at $405 \mathrm{~nm}$ spectrophotometrically. The determinations were performed using three replicates each time.

Hoechst stain assay for cell attachment: Hosechst 33342 DNA staining has been used to identify the cell attachment and growth on scaffold material [20]. For this, ethanol sterilized scaffold material was placed in the cell culture plate and seeded with MG 63 cells and incubated. After 4 days of culture, media was removed from the wells and washed with PBS solution. The cells were stained with $0.5 \mathrm{~mL}$ of Hoechst 33342 solutions $\left(3.5 \mu \mathrm{g} / \mathrm{mL}\right.$ in PBS) and incubated for $30 \mathrm{~min}$ at $37^{\circ} \mathrm{C}$. After $30 \mathrm{~min}$, the Hoechst stained cells were visualized and photographed under the Microscope-Olympus-version-6.0, Carl Zeiss lens, Germany.

Acridine orange stain assay for cell attachment: Acridine orange is used to identify both viable and apoptotic cells on scaffold materials [30]. For this, ethanol sterilized scaffold material was placed in the cell culture plate and seeded with MG 63 cells and incubated. After 4 days of culture, media was removed from the wells and washed with PBS solution. The cells were stained with $200 \mu \mathrm{L}$ of dye mixture $(100 \mu \mathrm{L} / \mathrm{mg}$ acridine orange distilled water). The suspension was immediately examined and viewed under Microscope-Olympusversion-6.0.

Compressive strength: The compressive strength of freeze dried scaffolds was obtained using universal testing machine (UTM). The tests were performed using the system Tinius Olsen, Model H5KS, UK. The $5000 \mathrm{~N}$ load cell with the standard grips of crosshead speed of $0.5 \mathrm{~mm} \mathrm{~min}^{-1}$ was used for the compression measurements. The determinations were performed using five replicates.

Statistical analysis: Statistical analysis for MTT and ALP assay were performed using Graph pad prism6 software. Results are presented as mean \pm standard deviation.

\section{RESULTS AND DISCUSSION}

Thermal stability: The thermal stability of the scaffolds was determined by TG analysis and shown in Fig. 1. The weight loss was observed between 30 to $120{ }^{\circ} \mathrm{C}$ in the scaffold material due to the evaporation of absorbed water molecules. Further, the major weight loss between 211 to $560{ }^{\circ} \mathrm{C}$ in chitosan/gellanHAP, 175 to $520^{\circ} \mathrm{C}$ in chitosan/alginate-HAP and 186 to 578 ${ }^{\circ} \mathrm{C}$ in chitosan/amylopectin-HAP was attributed to the thermal decomposition of chitosan, gellan, alginate and amylopectin into carbonaceous materials. The negligible amount of weight loss was observed above $600{ }^{\circ} \mathrm{C}$ due to the thermal stability of HAP [31-33]. Hence, the TG analysis proves the presence of all the individual components in the tricomponent scaffolds.

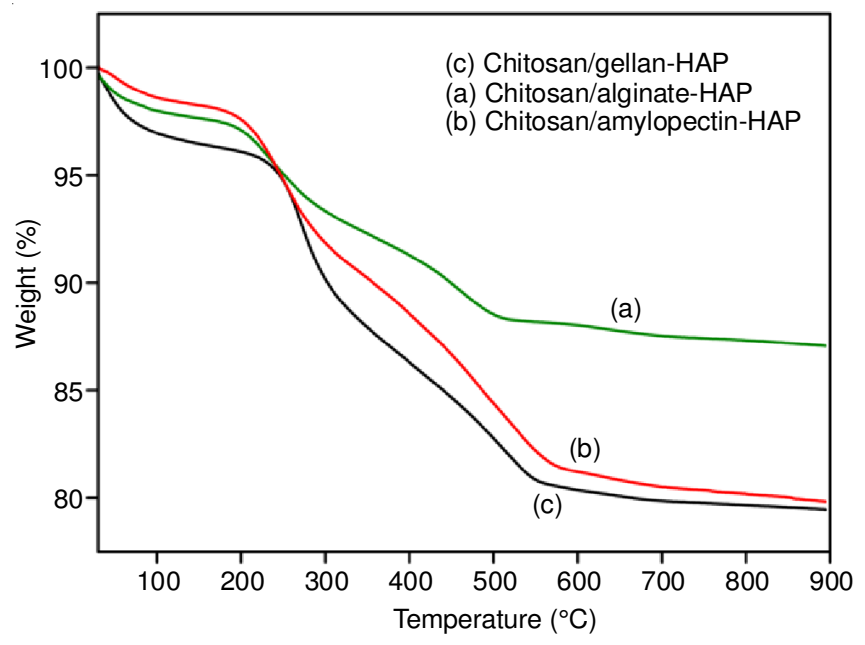

Fig. 1. TGA images of tricomponent scaffolds

FTIR analysis: FTIR spectra of all the raw materials as well as scaffolds were taken to identify the intermolecular interaction between the individual components present in the scaffold and shown in Fig. 2. The characteristic peaks observed in the FTIR spectrum of HAP (3570, 1460, 1049, 966, 881 and 634 $\mathrm{cm}^{-1}$ ) were well matched with the previously reported data $[18,20]$. The FTIR spectrum of chitosan showed all the characteristic stretching vibrations for $-\mathrm{OH}$ at $3464 \mathrm{~cm}^{-1}, \mathrm{C}=\mathrm{O}$ at $1641 \mathrm{~cm}^{-1}, \mathrm{C}-\mathrm{H}$ rocking at $1404 \mathrm{~cm}^{-1}, \mathrm{C}-\mathrm{O}$ group at 1256 $\mathrm{cm}^{-1}$, amine at $1155 \mathrm{~cm}^{-1}$ and $1099 \mathrm{~cm}^{-1}$ and pyranose C-O-C ring at $1050 \mathrm{~cm}^{-1}[4,20,33,34]$. Gellan showed the characteristic stretching vibrations for $-\mathrm{OH}$ at $3419 \mathrm{~cm}^{-1}, \mathrm{C}-\mathrm{H}$ at 2121 $\mathrm{cm}^{-1}$, asymmetric carboxylate at $1612 \mathrm{~cm}^{-1}$, symmetric carboxylate at $1400 \mathrm{~cm}^{-1}$ and pyranoside ring at $1047 \mathrm{~cm}^{-1}$ $[23,35,36]$. Alginate showed the characteristic stretching vibrations for $-\mathrm{OH}$ at $3414 \mathrm{~cm}^{-1}, \mathrm{C}-\mathrm{H}$ at $2924 \mathrm{~cm}^{-1}$, asymmetrical $\mathrm{COO}^{-}$at $1612 \mathrm{~cm}^{-1}$, symmetrical $\mathrm{COO}^{-}$at 1402 $\mathrm{cm}^{-1}$ and C-O-C (saccharide structure) at $1064 \mathrm{~cm}^{-1}[37,38]$. 

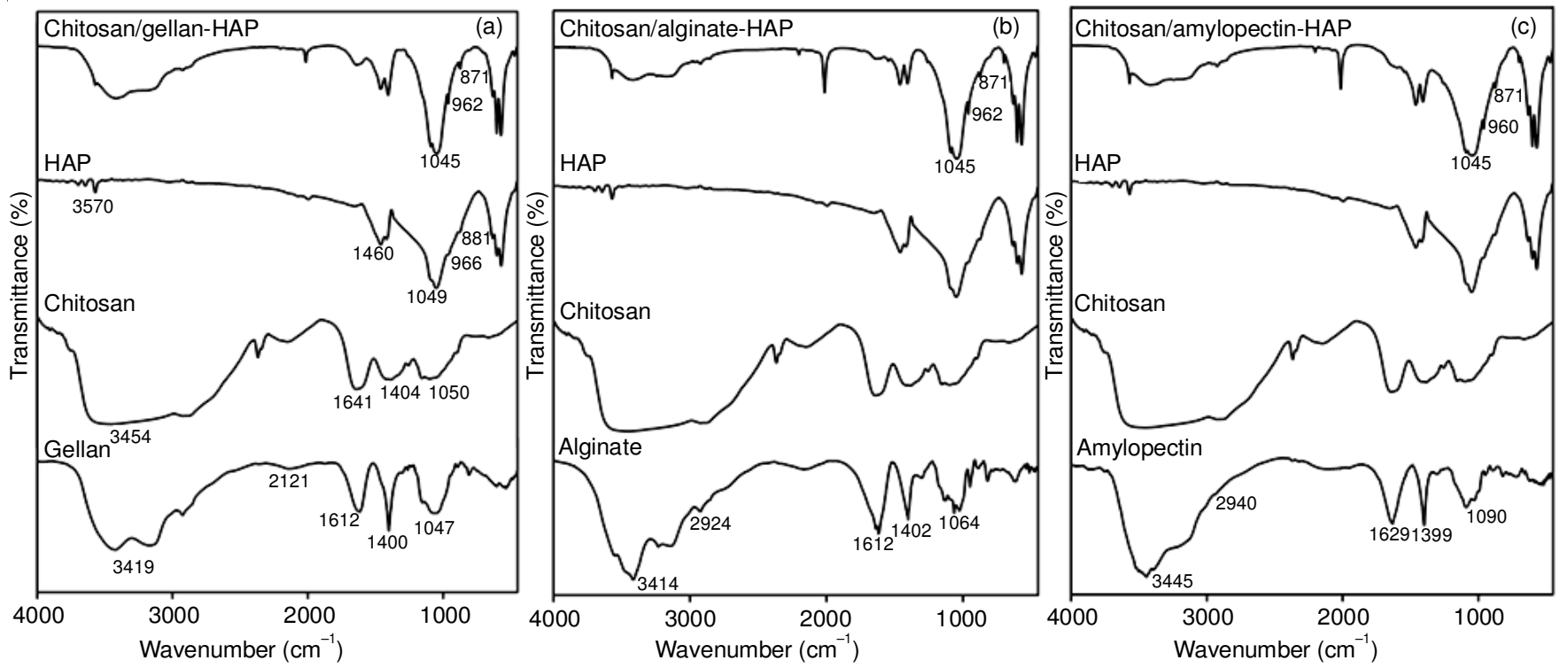

Fig. 2. FTIR spectra of (a) chitosan/gellan-HAP, (b) chitosan/alginate-HAP and (c) chitosan/amylopectin-HAP scaffolds

Amylopectin showed the characteristic stretching vibrations for $-\mathrm{OH}$ at $3445 \mathrm{~cm}^{-1}$, asymmetric C-H at $2940 \mathrm{~cm}^{-1}$, adsorbed water at $1629 \mathrm{~cm}^{-1}$, angular deformation of C-H at $1399 \mathrm{~cm}^{-1}$, $\mathrm{C}-\mathrm{O}$ ether at $1090 \mathrm{~cm}^{-1}$ and $\mathrm{C}-\mathrm{O}$ alcohol at $1028 \mathrm{~cm}^{-1}$ [20,39].

The FTIR spectrum of prepared scaffolds shows a combination of characteristics peaks similar to that of pristine chitosan, HAP, gellan, alginate and amylopectin along with absorption band at $3570 \mathrm{~cm}^{-1}$. This peak is assigned to the mixture of amine stretch from chitosan and to the -OH groups in HAP, gellan, alginate and amylopectin [40]. In chitosan/ gellan-HAP scaffold, HAP peaks were shifted from 1049 to $1045 \mathrm{~cm}^{-1}, 966$ to $962 \mathrm{~cm}^{-1}, 881$ to $873 \mathrm{~cm}^{-1}$ and 634 to 630 $\mathrm{cm}^{-1}$. In chitosan/alginate-HAP scaffold, HAP peaks were shifted from 1049 to $1045 \mathrm{~cm}^{-1}, 966$ to $962 \mathrm{~cm}^{-1}, 881$ to 871 $\mathrm{cm}^{-1}$ and 634 to $632 \mathrm{~cm}^{-1}$. In chitosan/amylopectin-HAP scaffold, HAP peaks were shifted from 1049 to $1045 \mathrm{~cm}^{-1}$, 966 to $960 \mathrm{~cm}^{-1}, 881$ to $871 \mathrm{~cm}^{-1}$ and 634 to $632 \mathrm{~cm}^{-1}$. Besides, the FTIR spectra also indicated the shifting of characteristic peaks of C-O and amine in chitosan as well as the characteristic peaks of gellan, alginate and amylopectin. These results suggest the strong interaction between chitosan and HAP along with other polysaccharides for example electrostatic interactions between $-\mathrm{NH}_{3}{ }^{+}$and $\mathrm{PO}_{4}{ }^{3-}$ and between $\mathrm{C}-\mathrm{O}$ and $\mathrm{Ca}^{2+}$. The shifting of HAP peak at $1049 \mathrm{~cm}^{-1}$ evidences the strong hydrogen bonding interactions between HAP and polysaccharides. Hence, the shift in peak values was observed in all scaffold material confirming the existence of active electrostatic interactions and hydrogen bonding between individual components and formation of tricomponent scaffolds [20,32,41].

XRD analysis: XRD pattern for chitosan, gellan, alginate, amylopectin, HAP and scaffolds were carried out as shown in Fig. 3. The XRD pattern for isolated HAP was found to be crystalline and in good conformity with the standard values of HAP (JCPDS-09-0432/1996) [18]. The XRD pattern showed an amorphous peak for chitosan at $10.7^{\circ}$ and $20.0^{\circ}$, gellan at $19.34^{\circ}$, alginate at $13.57^{\circ}$ and amylopectin at $13.62^{\circ}$.
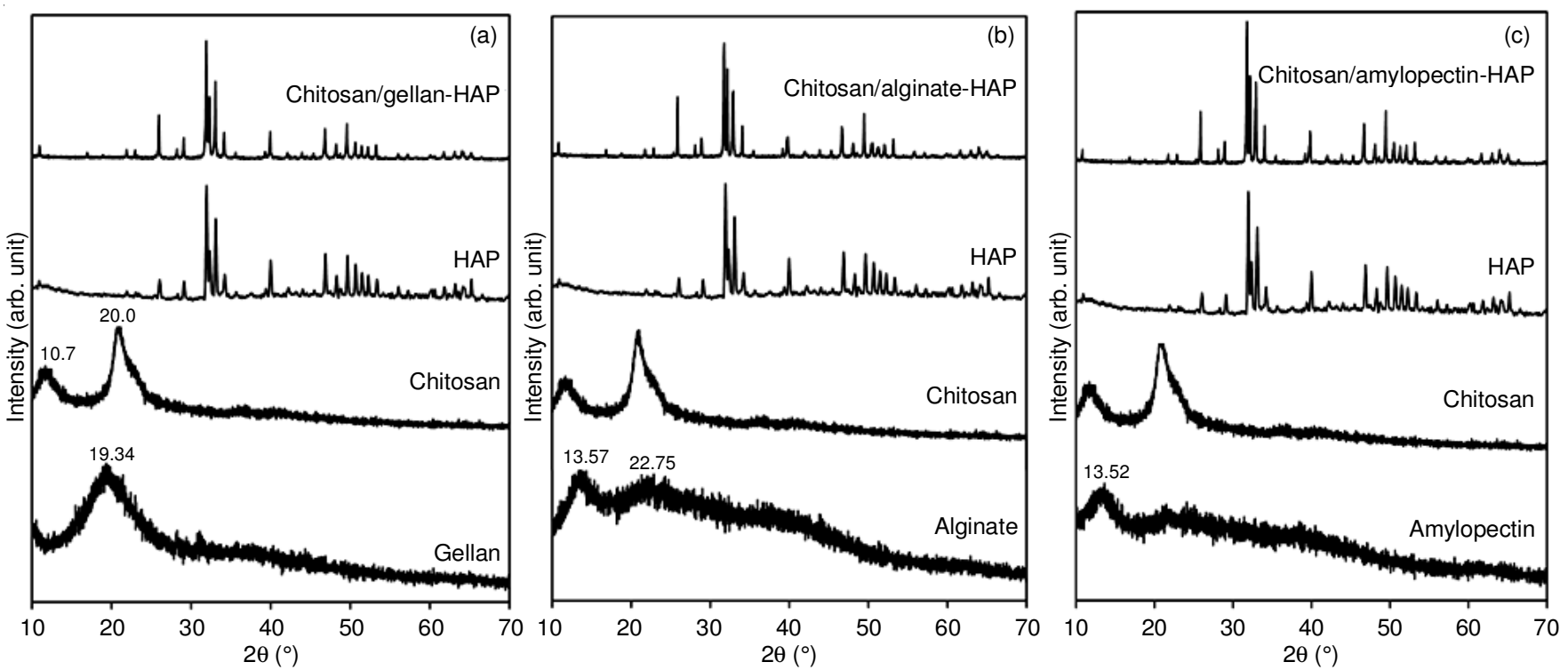

Fig. 3. XRD pattern of (a) chitosan/gellan-HAP, (b) chitosan/alginate-HAP and (c) chitosan/amylopectin-HAP scaffolds 
The major peak for HAP at $26.05^{\circ}, 31.95^{\circ}$ and $39.99^{\circ}$ were shifted to $25.96^{\circ}, 31.90^{\circ}$ and $39.94^{\circ}$ in chitosan/gellan-HAP, $25.88^{\circ}, 31.78^{\circ}$ and $39.83^{\circ}$ in chitosan/alginate-HAP and $25.86^{\circ}, 31.78^{\circ}$ and $39.81^{\circ}$ in chitosan/amylopectin-HAP along with reduced peak intensity for chitosan, gellan, alginate and amylopectin. The lower crystallinity of HAP in scaffolds suggests that the crystallographic structures were more similar to natural bone mineral (biological apatite). The lower crystallininty of HAP and reduced intensity of polysaccharides was due to the ionic interaction between amorphous polysaccharides and HAP as like collagen and HAP in natural bone mineral [20,42].

Morphology and porosity analysis: Porosity and pore size are important parameters for tissue engineering application to create a better cell proliferations, differentiations and adhesion. Morphology of HAP, chitosan/gellan-HAP, chitosan/alginateHAP and chitosan/amylopectin-HAP were analyzed by FESEM and the images are shown in Fig. 4. FE-SEM images of HAP (Fig. 4a) showed the flake-like structure of crystalline HAP with crystal size of 300-400 $\mathrm{nm}$. While the freeze dried scaffold materials showed porous morphology and the pore size was found to be 46-180 $\mu \mathrm{m}$ for chitosan/gellan-HAP, 77$244 \mu \mathrm{m}$ for chitosan/alginate-HAP and 76-106 $\mu \mathrm{m}$ for chitosan/ amylopectin-HAP. Further, FE-SEM images evidenced the homogeneous dispersion of HAP over polysaccharides.

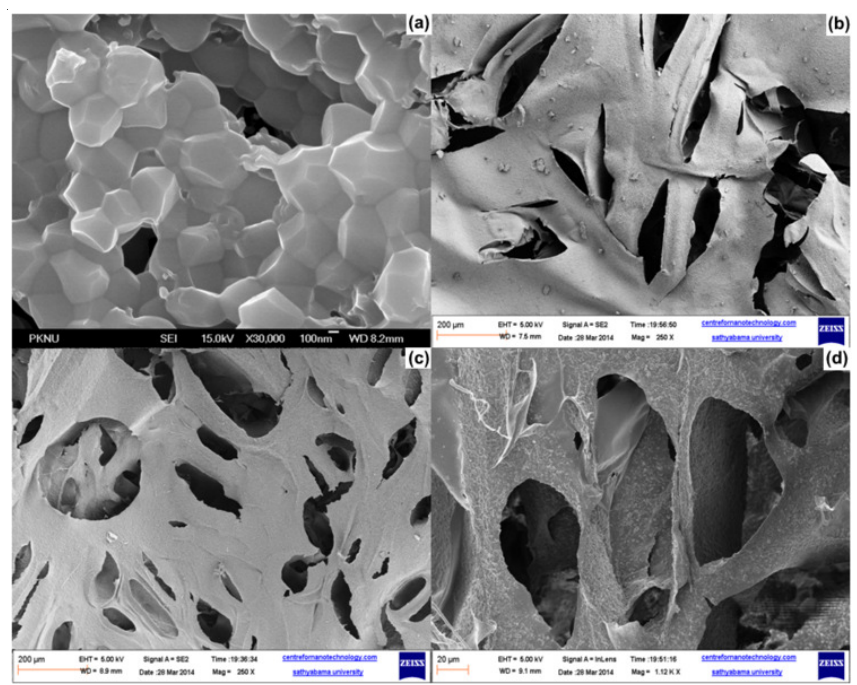

Fig. 4. FE-SEM images of (a) HAP (b) chitosan/gellan-HAP, (c) chitosan/ alginate-HAP and (d) chitosan/amylopectin-HAP scaffolds

Total porosity is a crucial factor for adequate cell invasion, transport of nutrients and waste and transduction of cellular signals. It has been reported that porosity acts as a favourable condition for cells viability especially in tissue in-growth. The total porosity of the scaffolds were obtained by the liquid displacement method and found to be $91.02 \%$ for chitosan/ gellan-HAP, $90.60 \%$ for chitosan/alginate-HAP and $88.41 \%$ for chitosan/amylopectin-HAP. These values could meet the requirement of $90 \%$ porosity for bone tissue engineering. Among them, chitosan/gellan-HAP poses higher porosity and can be useful to facilitate faster cell proliferation [20,43].

In vitro cytotoxicity analysis: In order to find out the biocompatibility, a preliminary biological investigation was carried out on prepared tricomponent scaffolds. The test was performed in vitro by seeding MG 63 cells on to surface of the scaffolds. Fig. 5 shows the cell proliferation levels of MG 63 cell on the scaffolds based on different time interval. It was clear that the cells on the scaffolds proliferated well and resulted in increasing cell viability with increasing days, mainly due to the porous structures. The porous structure of the prepared tricomponent scaffolds allowed a spatial arrangement of cells to attach them easily and proliferated well. Further, the hydrophilic groups present in polysaccharides involved in the active interactions with cells for the cell growth. There was no significant difference in cell viability among the tricomponent scaffolds for the first two days, but there was higher cell viability for chitosan/gellan-HAP during 3rd and 4th day when compared with chitosan/alginate-HAP and chitosan/amylopectin-HAP scaffold. The higher porosity exhibited by chitosan/gellan-HAP is expected to increase the cell penetration and diffusion of mass transport requirements of nutrient, metabolities and soluble signals that could provide optimal growth conditions and eventually lead to faster cell proliferation inside the scaffold [44-46]. The observed results revealed that the tested tricomponent scaffolds do not have any acute cytotoxic effect and can be served as biomaterials for bone tissue engineering.

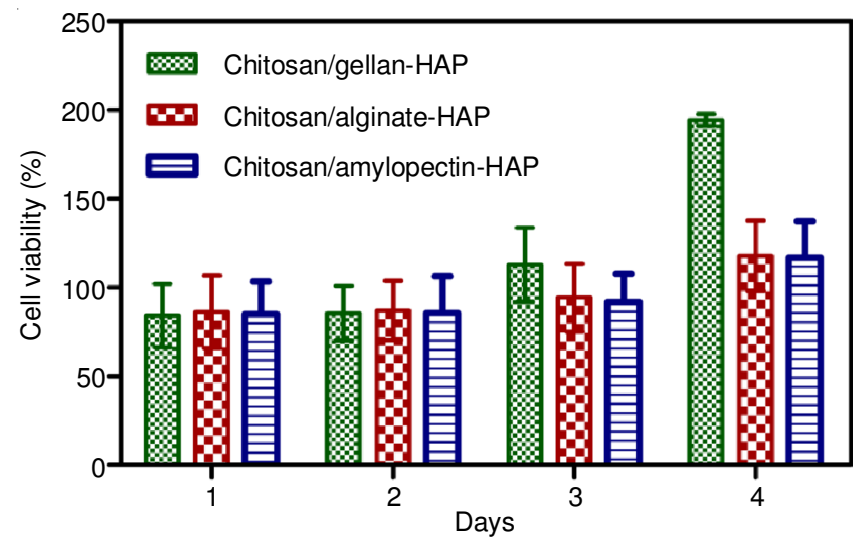

Fig. 5. In vitro MTT assay of chitosan/gellan-HAP, chitosan/alginate-HAP and chitosan/amylopectin-HAP scaffolds on MG 63 cell line as a function of days. Values are expressed as mean \pm standard deviation $(\mathrm{P}<0.0001, \mathrm{n}=3)$

Alkaline phosphatase assay: Alkaline phosphatase activity is widely used as a marker for early differentiation and mineralization of osteoblast-like cells, which promotes mineralization by increasing the local concentration of inorganic phosphate ion and/or by decreasing the concentration of the mineralization inhibitor phosphate [47-49]. Generally, chitosan is known to increase the ALP expression of osteoblast cells [50]. The mineralization on the chitosan based tricomponent scaffolds were quantitatively determined by ALP activity over a cultivation period of 2nd and 4th day and shown in Fig. 6. The cells had almost similar increasing ALP activity on the tricomponent scaffolds as a function of days. Among the scaffolds, chitosan/ gellan-HAP scaffold showed slightly higher ALP activity on the fourth day due to higher porosity. The increasing mineralization and better bone bioactivity of tricomponent scaffolds were proved from the assessments of ALP activity. As mentioned in MTT assay, porosity of the tricomponent scaffolds played a crucial factor in cell proliferation and mineralization. 


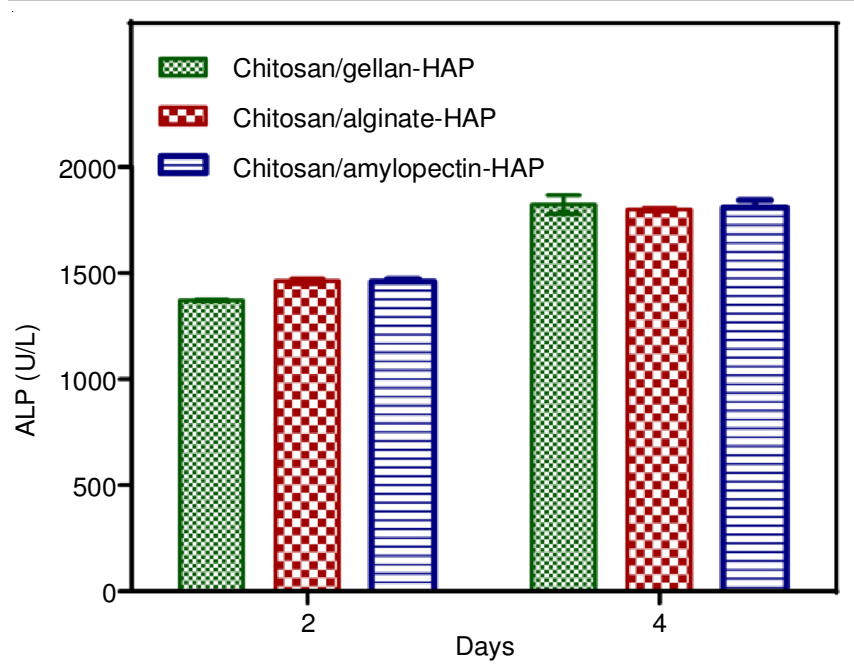

Fig. 6. ALP activity of chitosan/gellan-HAP, chitosan/alginate-HAP and chitosan/amylopectin-HAP scaffolds on MG 63 cell line. Values are expressed as mean \pm standard deviation $(\mathrm{P}<0.0001, \mathrm{n}=3)$

Cell adhesion on scaffolds: Cell adhesion on the scaffold represents the initial phase of cell-scaffold communication that subsequently affects cell differentiation [51]. Hoechst 33342 DNA stain and acridine orange dyes were used to visualize the live MG 63 cells on tricomponent scaffolds under fluorescence microscope. From the fluorescence microscopic images of Hoechst stain, as shown in Fig. 7(a-c) and acridine orange Fig. 7(d-f), it was clear that MG 63 cells are adhered well and proliferated on the tricomponent scaffolds on the $4^{\text {th }}$ day. The electrostatic interaction between positively charged chitosan and negatively charged cell membranes of prepared chitosan based tricomponent scaffolds played a pivotal role for better cell attachment. The cells secreted ECM with increasing culture time, whereas the cells were able to adhere, grow and spread on the scaffold surface. Chitosan/gellan-HAP scaffolds (Fig. 7a $\&$ d) showed denser cell attachment compared with other two scaffolds due to the higher porosity, which is well correlated with MTT assay [44,52]. These results revealed that the porosity and positively charged chitosan present in scaffolds enhanced the cell adhesion and proliferation.

Compressive strength: The construct of scaffold should be maintained after seeding the cells since the scaffold has to be mechanically strong to provide physical strength and flexibility to the bone as well as to support extensive vascularization, cell proliferation, differentiation and new tissue formation [23]. To evaluate the mechanical strength of the prepared tricomponent scaffolds, compressive strength studies were carried out and results are shown in Fig. 8. Compressive strength value was found to be $143.80 \pm 6.4 \mathrm{KPa}$ for chitosan/gellan-HAP, $88.52 \pm 2.4 \mathrm{KPa}$ for chitosan/alginate-HAP and $81.30 \pm 5.8$ for chitosan/amylopectin-HAP scaffolds. The difference in compressive strength value was mainly due to the difference in porosity and pore size of the scaffolds and viscosity of polysaccharide. During experiment, it was observed that gellan based tricomponent solution showed a highly viscous nature when compared with alginate and amylopectin solutions. The higher viscous nature of gellan induced shorter gelation time, which produced more jelly like solution and resulted in a dense layer of harder scaffold after lyophilization.
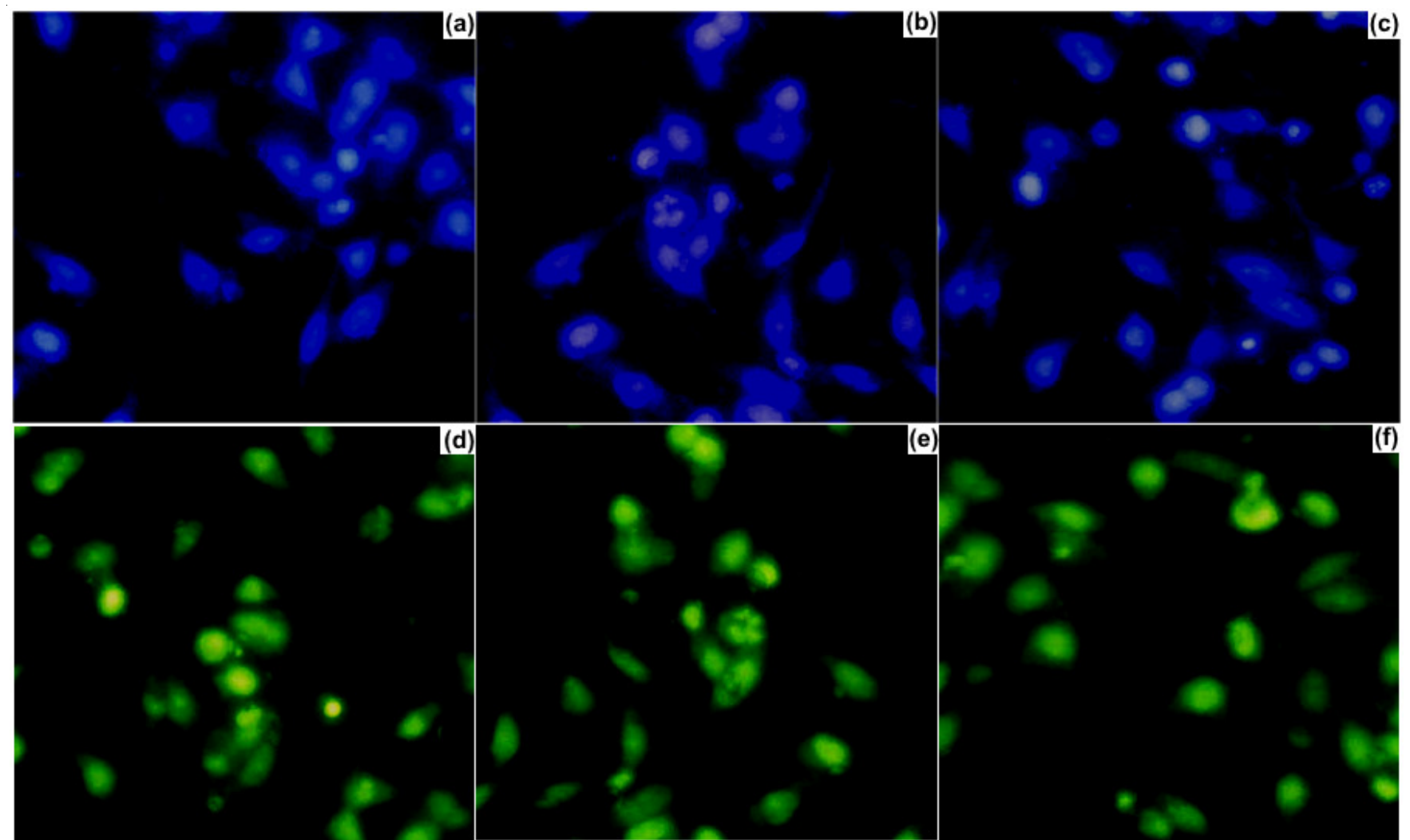

Fig. 7. Optical microscopy images of Hoechst 3342 stained cells grown on (a) chitosan/gellan-HAP, (b) chitosan/alginate-HAP and (c) chitosan/amylopectin-HAP scaffolds and acridine orange stained cells grown on (e) chitosan/gellan-HAP, (f) chitosan/alginate-HAP and $(\mathrm{g})$ chitosan/amylopectin-HAP scaffolds 


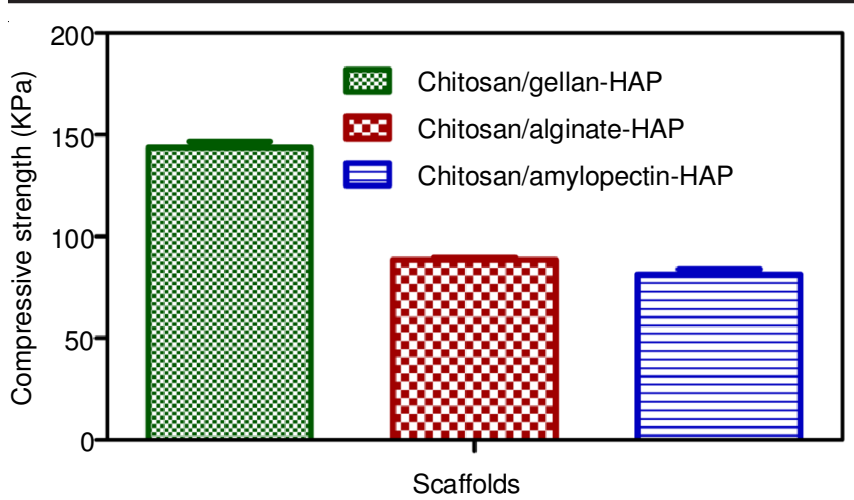

Fig. 8. Compressive strength images of tricomponent scaffolds. Values are expressed as mean \pm standard deviation $(n=5)$

\section{Conclusion}

Polysaccharides have gained fascinating attention towards tissue engineering due to their similarity with ECM, chemical versatility and good biological performance. However, the combination of polysaccharides with bioactive inorganic materials can be a promising material for bone tissue engineering. In this work, polysaccharide based porous tricomponent scaffolds of chitosan/gellan-HAP, chitosan/alginate-HAP and chitosan/amylopectin-HAP were prepared by freeze drying method and characterized. FTIR and XRD analysis confirmed the formation of composite through strong electrostatic interaction and hydrogen bonding between the components present in the scaffolds where as FE-SEM images evidenced the porous morphology of the scaffolds. In vitro studies on MG 63 cell line proved that the prepared tricomponent scaffolds have better cell adhesion, proliferation and mineralization. We found that the porosity of the scaffolds plays an important role in bone tissue engineering because of the higher cell proliferation and mineralization exhibited by chitosan/gellanHAP scaffold due to the higher porosity. The compressive strength is mainly depends upon the viscosity of the polysaccharides and porosity. Hence, the prepared tricomponent scaffolds can hold a promising role in bone tissue engineering.

\section{ACKNOWLEDGEMENTS}

The authors acknowledge the powder XRD facility at SAS, Vellore Institute of Technology (VIT), jointly funded by VIT and FIIST, DST India.

\section{REFERENCES}

1. H. Shin, S. Jo and A.G. Mikos, Biomaterials, 24, 4353 (2003); https://doi.org/10.1016/S0142-9612(03)00339-9.

2. D. Dyondi, T.J. Webster and R. Banerjee, Int. J. Nanomedicine, 8, 47 (2013); https://doi.org/10.2147/IJN.S37953.

3. M.B. Eslaminejad and F. Bagheri, Yakhteh Med. J., 11, 263 (2009).

4. R. Rajesh, A. Hariharasubramanian, N. Senthilkumar and Y.D. Ravichandran, Int. J. Pharm. Pharm. Sci., 4, 716 (2012).

5. K.J.L. Burg, S. Porter and J.F. Kellam, Biomaterials, 21, 2347 (2000); https://doi.org/10.1016/S0142-9612(00)00102-2.

6. F.F. Azhar, A. Olad and R. Salehi, Des. Monomers Polym., 17, 654 (2014); https://doi.org/10.1080/15685551.2014.907621

7. P. Coimbra, P. Ferreira, H.C. de Sousa, P. Batista, M.A. Rodrigues, I.J. Correia and M.H. Gil, Int. J. Biol. Macromol., 48, 112 (2011); https://doi.org/10.1016/j.ijbiomac.2010.10.006.

8. A. Autissier, C.L. Visage, C. Pouzet, F. Chaubet and D. Letourneur, Acta Biomater., 6, 3640 (2010); https://doi.org/10.1016/j.actbio.2010.03.004.
9. L. Bacakova, K. Novotna and M. Parizek, Physiol. Res., 63, S29 (2014).

10. F. Khan and S.R. Ahmad, Macromol. Biosci., 13, 395 (2013); https://doi.org/10.1002/mabi.201200409.

11. J.F. Mano, G.A. Silva, H.S. Azevedo, P.B. Malafaya, R.A. Sousa, S.S. Silva, L.F. Boesel, J.M. Oliveira, T.C. Santos, A.P. Marques, N.M. Neves and R.L. Reis, J. Royal Soc. Interface, 4, 999 (2007); https://doi.org/10.1098/rsif.2007.0220.

12. F.M.P. Tonelli, A.K. Santos, K.N. Gomes, E. Lorencon, S. Guatimosim, L.O. Ladeira and R.R. Resende, Int. J. Nanomedicine, 7, 4511 (2012); https://doi.org/10.2147/IJN.S33612.

13. J.C. Fricain, S. Schlaubitz, C. Le Visage, I. Arnault, S.M. Derkaoui, R. Siadous, S. Catros, C. Lalande, R. Bareille, M. Renard, T. Fabre, S. Cornet, M. Durand, A. Léonard, N. Sahraoui, D. Letourneur and J. Amédée, Biomaterials, 34, 2947 (2013); https://doi.org/10.1016/j.biomaterials.2013.01.049.

14. S.M. Oliveira, R.L. Reis and J.F. Mano, ACS Biomater. Sci. Eng., 1, 2 (2015); https://doi.org/10.1021/ab500006x.

15. V. Mourino and R. Boccaccini, J. Royal Soc. Interface, 7, 209 (2010); https://doi.org/10.1098/rsif.2009.0379.

16. M. Salehi, M.N. Nosar, A. Amani, M. Azami, S. Tavakol and H. Ghanbari, Int. J. Polym. Mater. Polym. Biomater., 64, 675 (2015); https://doi.org/10.1080/00914037.2014.1002093.

17. I. Armentano, M. Dottori, E. Fortunati, S. Mattioli and J.M. Kenny, Polym. Degrad. Stab., 95, 2126 (2010); https://doi.org/10.1016/j.polymdegradstab.2010.06.007.

18. R. Rajesh, A. Hariharasubramanian and Y.D. Ravichandran, Phosphorus Sulfur Silicon Relat. Elem., 187, 914 (2012); https://doi.org/10.1080/10426507.2011.650806.

19. Z.H. Derakhshan, B. Shaghaghi, M.P. Asl, M. Majidi, L. Ghazizadeh, A. Chegini and S. Bonakdar, Int. J. Polym. Mater. Polym. Biomater., 64, 919 (2015) https://doi.org/10.1080/00914037.2015.1030662.

20. J. Venkatesan, R. Pallela, I. Bhatnagar and S.-K. Kim, Int. J. Biol. Macromol., 51, 1033 (2012); https://doi.org/10.1016/j.ijbiomac.2012.08.020.

21. J. Venkatesan, Z.-J. Qian, B.M. Ryu, N. Ashok Kumar and S.-K. Kim, Carbohydr. Polym., 83, 569 (2011); https://doi.org/10.1016/j.carbpol.2010.08.019.

22. R. Rajesh, N. Senthilkumar, A. Hariharasubramanian and Y.D. Ravichandran, Int. J. Pharm. Pharm. Sci., 4, 23 (2012).

23. J. Roman, M.V. Cabanas, J. Pena and M.V. Regi, Sci. Tech. Adv. Mater, 12, 045003 (2011).

24. S.B. Lee, Y.H. Kim, M.S. Chong, S.H. Hong and Y.M. Lee, Biomaterials, 26, 1961 (2005); https://doi.org/10.1016/i.biomaterials.2004.06.032.

25. S.-N. Park, J.-C. Park, H.O. Kim, M.J. Song and H. Suh, Biomaterials, 23, 1205 (2002); https://doi.org/10.1016/S0142-9612(01)00235-6.

26. Z. Li, H.R. Ramay, K.D. Hauch, D. Xiao and M. Zhang, Biomaterials, 26, 3919 (2005); https://doi.org/10.1016/j.biomaterials.2004.09.062.

27. J. Zhang, J. Nie, Q. Zhang, Y. Li, Z. Wang and Q.J. Hu, Biomater. Sci. Polym., 25, 61 (2014); https://doi.org/10.1080/09205063.2013.836950.

28. H.R. Lin and Y.J.J. Yeh, Biomed. Mater. Res. Part B: Appl. Biomater, 71, 52 (2004); https://doi.org/10.1002/jbm.b.30065.

29. N. Ramalingam, T.S. Natarajan and S.J. Rajiv, Biomed. Res. A, 103, 16 (2015).

30. D. Baskic, S. Popovic, P. Ristic and N.N. Arsenijevic, Cell Biol. Int., 30, 924 (2006); https://doi.org/10.1016/j.cellbi.2006.06.016

31. N. Barbani, M.L. Coluccio, C. Cristallini, G.D. Guerra and E. Rosellini, J. Appl. Polym. Sci., 118, 3131 (2010); https://doi.org/10.1002/app.32277.

32. M. Ionita, M.A. Pandele and H. Iovu, Carbohydr. Polym., 94, 339 (2013); https://doi.org/10.1016/j.carbpol.2013.01.065.

33. R. Rajesh, Y.D. Ravichandran, N.A. Nambi Raj and N. Senthilkumar, Polym-Plast. Technol., 53, 1105 (2014); https://doi.org/10.1080/03602559.2014.886075.

34. C. Tang, N. Chen, Q. Zhang, K. Wang, Q. Fu and X. Zhang, Polym. Degrad. Stab., 94, 124 (2009); https://doi.org/10.1016/j.polymdegradstab.2008.09.008. 
35. R. Rajesh and Y.D. Ravichandran, RSC Adv., 5, 41135 (2015); https://doi.org/10.1039/C5RA07015E.

36. G. Ciardelli, V. Chiono, G. Vozzi, M. Pracella, A. Ahluwalia, N. Barbani, C. Cristallini and P. Giusti, Biomacromolecules, 6, 1961 (2005); https://doi.org/10.1021/bm0500805.

37. L. Wang, Y. Li and C.J. Li, Nanopart. Res., 11, 691 (2009); https://doi.org/10.1007/s11051-008-9431-y.

38. D. Leal, B. Matsuhiro, M. Rossi and F. Caruso, Carbohydr. Res., 343, 308 (2008); https://doi.org/10.1016/j.carres.2007.10.016

39. D.C. Dragunski and A. Pawlicka, Mater. Res., 4, 77 (2001); https://doi.org/10.1590/S1516-14392001000200006.

40. D. Han, L. Yan, W. Chen and W. Li, Carbohydr. Polym., 83, 653 (2011); https://doi.org/10.1016/j.carbpol.2010.08.038.

41. S. Dasgupta and K. Maji, International Conference on Advances in Engineering and Technology (ICAET'2014), p. 474 (2014).

42. L. Chen, J. Hu, J. Ran, X. Shen and H. Tong, Int. J. Biol. Macromol., 65, 1 (2014); https://doi.org/10.1016/j.ijbiomac.2014.01.003.

43. S. Pok, F. Vitale, S.L. Eichmann, O.M. Benavides, M. Pasquali and J.G. Jacot, ACS Nano, 8, 9822 (2014); https://doi.org/10.1021/nn503693h.

44. H. Liao, R. Qi, M. Shen, X. Cao, R. Guo, Y. Zhang and X. Shi, Colloids Surf. B Biointerfaces, 84, 528 (2011); https://doi.org/10.1016/j.colsurfb.2011.02.010.
45. Y.-J. Seol, J.-Y. Lee, Y.-J. Park, Y.-M. Lee, Y. -Ku, I.-C. Rhyu, S.-J. Lee, S.-B. Han and C.-P. Chung, Biotechnol. Lett., 26, 1037 (2004); https://doi.org/10.1023/B:BILE.0000032962.79531.fd.

46. G. Vozzi, C. Corallo, S. Carta, M. Fortina, F. Gattazzo, M. Galletti and N. Giordano, J. Biomed. Mater. Res. A, 102A, 1415 (2014); https://doi.org/10.1002/jbm.a.34823.

47. L. Kong, Y. Gao, G. Lu, Y. Gong, N. Zhao and X. Zhang, Eur. Polym. J., 42, 3171 (2006); https://doi.org/10.1016/j.eurpolymj.2006.08.009.

48. X. Hu, K.-G. Neoh, Z. Shi, E.-T. Kang, C. Poh and W. Wang, Biomaterials, 31, 8854 (2010); https://doi.org/10.1016/j.biomaterials.2010.08.006.

49. M. Wiens, T.A. Elkhooly, H.-C. Schroder, T.H.A. Mohamed and W.E.G. Muller, Acta Biomater, 10, 4456 (2014); https://doi.org/10.1016/j.actbio.2014.06.036.

50. P.-H. Chua, K.-G. Neoh, E.-T. Kang and W. Wang, Biomaterials, 29, 1412 (2008); https://doi.org/10.1016/j.biomaterials.2007.12.019.

51. H.B. Ma, W.X. Su, Z.X. Tai, D.F. Sun, X.B. Yan, B. Liu and Q.J. Xue, Chin. Sci. Bull., 57, 3051 (2012); https://doi.org/10.1007/s11434-012-5336-3.

52. Y. Chen, Y. Qi, Z. Tai, X. Yan, F. Zhu and Q. Xue, Eur. Polym. J., 48, 1026 (2012);

https://doi.org/10.1016/j.eurpolymj.2012.03.011. 